Abstracta Iranica Abstracta Iranica

Revue bibliographique pour le domaine irano-aryen

Volume 30 | 2010

Comptes rendus des publications de 2007

\title{
Un autre islam. Inde, Pakistan, Bangladesh. Paris, Albin Michel, 2007, 389 p. (Collection Planète Inde)
}

\section{Fabrizio Speziale}

\section{(2) OpenEdition}

1 Journals

\section{Édition électronique}

URL : http://journals.openedition.org/abstractairanica/37904

DOI : 10.4000/abstractairanica.37904

ISSN : 1961-960X

Éditeur :

CNRS (UMR 7528 Mondes iraniens et indiens), Éditions de l'IFRI

\section{Édition imprimée}

Date de publication : 8 avril 2010

ISSN : 0240-8910

\section{Référence électronique}

Fabrizio Speziale, «Un autre islam. Inde, Pakistan, Bangladesh. Paris, Albin Michel, 2007, 389 p.

(Collection Planète Inde) », Abstracta Iranica [En ligne], Volume 30 |2010, document 215, mis en ligne le 08 avril 2010, consulté le 26 septembre 2020. URL : http://journals.openedition.org/ abstractairanica/37904; DOI : https://doi.org/10.4000/abstractairanica.37904

Ce document a été généré automatiquement le 26 septembre 2020.

Tous droits réservés 


\title{
Un autre islam. Inde, Pakistan, Bangladesh. Paris, Albin Michel, 2007, 389 p. (Collection Planète Inde)
}

\author{
Fabrizio Speziale
}

Cet ouvrage de Marc Gaborieau comble une lacune importante : le monde musulman du sous-continent indien, en dépit de son importance, a été rarement l'objet d'études systématiques capables de s'adresser non seulement au groupe restreint des spécialistes, mais également à un public plus large. L'ouvrage analyse la spécificité et la complexité de l'islam indien, son histoire, sa société, ses courants religieux, ses institutions, et ses grands paradoxes, dont le plus étonnant est certainement le fait que les musulmans du sous-continent constituent la plus grande masse de la population musulmane mondiale, mais sont en même temps une minorité dans leur région. L'A. remarque qu'il faut reconsidérer certains mythes, comme celui de la naissance de la conception de l'Etat islamique, qui est en réalité un produit des grands changements déterminés par l'époque coloniale, et l'idée que la structure de la société musulmane locale se différencie complètement de la société indienne, en vertu de son égalitarisme. Le fait que la plupart de la population restait hindoue, nonobstant les nombreux siècles de domination musulmane, ne signifie pas que les musulmans restèrent en Inde un corps étranger, isolé du monde local, mais bien au contraire, comme le montre l'A. en présentant les formes à travers lesquelles l'islam s'adapta de façon innovante au milieu local. La première partie offre un rétrospective historique des treize siècles d'islam en Inde, dès les premières incursions armées jusqu'à l'époque coloniale (pp. 23-83); la deuxième est dédiée au milieu religieux : écoles, minorités courants mystiques, au rôle des différents groupes ethniques : touraniens, iraniens, afghans et au reflux plus tardif de l'influence arabe (pp. 85-157). La partie suivante offre une large analyse comparative des structures et hiérarchies sociales des musulmans indiens et des hindous (pp. 159-213) ; enfin, dans la quatrième partie, sont analysés les forces et les événements qui portèrent à la partition, et l'éventail des institutions étatiques qui ont été fondées dans 
la région après 1947 (pp. 215-294). L'épilogue est constitué par un roman ethnographique, intitulé "Un homme, une femme ", décrivant la vie de deux jeunes appartenant à deux castes différentes, qui vivent dans un village de l'Uttar Pradesh (pp. 295-322). Le volume est illustré par des cartes historiques, des tableaux et est accompagné d'une chronologie (pp. 351-362) et d'un glossaire des termes (pp. 363-373).

INDEX

Thèmes : 7. Islam

\section{AUTEURS}

\section{FABRIZIO SPEZIALE}

Pontificia Università Gregoriana - Rome 